\title{
TEMPORAL PARTITIONING OF DIURNAL BEHAVIOURAL PATTERNS OF CORIS JULIS AND DIPLODUS VULGARIS (ACTINOPTERYGII: PERCIFORMES) IN MEDITERRANEAN CORALLIGENOUS HABITATS
}

\author{
Fanny WITKOWSKI*, Aurélie VION, and Marc BOUCHOUCHA \\ Ifremer, Laboratoire Environnement Ressources Provence Azur Corse, Zone portuaire de Brégaillon, \\ 83507 La Seyne-sur-Mer, France
}

\begin{abstract}
Witkowski F., Vion A., Bouchoucha M. 2016. Temporal partitioning of diurnal behavioural patterns of Coris julis and Diplodus vulgaris (Actinopterygii: Perciformes) in Mediterranean coralligenous habitats. Acta Ichthyol. Piscat. 46 (3): 171-183.
\end{abstract}

\begin{abstract}
Background. There is need for more information on behavioural rhythms of fishes in relation to their habitat use in few or not previously monitored areas, such as coralligenous habitats. Some studies have compiled inventories of observable fish species in this habitat, but no studies have been performed on the temporal patterning of fish behaviour, especially at the scale of the day. The presently reported study aims at providing knowledge on finescale fluctuations of abundances and behaviour of two fish species in coralligenous habitats throughout the diurnal period.

Materials and methods. Fish fauna was filmed hourly, for several days, from dusk to dawn, with autonomous, programmable, and rotating video systems. Diurnal variations in abundances per count, considering size classes and behaviour, were studied for two diurnal fish species - the Mediterranean rainbow wrasse, Coris julis (Linnaeus, 1758) (Labridae), and the common two-banded seabream, Diplodus vulgaris (Geoffroy Saint-Hilaire, 1817) (Sparidae) in two study areas of coralligenous habitats on the French Riviera.

Results. Significant temporal variability at the scale of the hour was revealed for abundances of $C$. julis in one of the two study areas, with few individuals in crepuscular periods and highest abundances in the morning and in the afternoon. These differences were mainly due to significant diurnal variations in abundances of small and medium C. julis, which were low in crepuscular periods, whereas large-sized individuals were equally abundant during the day. On the other hand, no discernible diurnal rhythmicity of mean abundances of $D$. vulgaris was observed, regardless of the study area. Crepuscular periods were associated with sudden changes of abundances and behaviour for both species, with a greater percentage of mobile and solitary individuals, and few feeding individuals compared to the rest of the day. Feeding occurred mainly in the morning for C. julis. In contrast, no dial-time preference for feeding was revealed for $D$. vulgaris.

Conclusions. The study provided preliminary insights into fine-scale diurnal variations of abundances of different life stages and of fish behaviour. Variability in abundances of life stages and of fish behaviours at different times of day should be taken into account for population assessments and spatial comparisons. Moreover, our study confirmed the use of video-imaging as an efficient non-destructive tool for the study of fish fauna in structurally complex, highly valuable habitats.
\end{abstract}

Keywords: activity rhythms, ethology, fish, bioherm, underwater video

\section{INTRODUCTION}

Light intensity and photoperiod drive the activity rhythms of marine organisms, especially highly mobile animals such as fishes (Horodysky et al. 2008). In the wild, animals time their activities to coincide with what for them is the most advantageous phase of the solar day, a concept widely known as biological rhythm (Reebs 2002). Differences in the diel distribution of fish assemblages have been related to several driving forces: feeding (Polunin and Klumpp 1989, Piet and Guruge 1997,
Carpentieri et al. 2005), predator avoidance (Nagelkerken et al. 2000, Hammerschlag et al. 2010), shelter seeking (Hobson 1972), social interactions (Fréon et al. 1996, Bégout Anras et al. 1997), and reproductive behaviours (Samoilys 1997). Although the diel rhythms of some fish species are well known under controlled laboratory conditions, studies under natural conditions remain scarce (Willis et al. 2006, Azzurro et al. 2013, Myers et al. 2016), partly due to observational challenges in the marine environment. However, there is need for more information

* Correspondance: Fanny Witkowski, Ifremer LER-PAC, Zone portuaire de Bregaillon, 83507 La Seyne-sur-Mer, France, phone: +33 787439330, e-mail: (FW) fanny.witkowski@ifremer.fr, (AV) vion.aurelie@hotmail.fr, (MB) marc.bouchoucha@ifremer.fr. 
on behavioural rhythms in relation to the habitat use of fishes in few or not previously monitored areas, especially highly ecologically valuable habitats.

Coralligenous habitats represent one of the most important biodiversity "hot spots" in the Mediterranean Sea (Giakoumi et al. 2013). They are composed of complex stratified structures of calcareous sciaphilic organisms, which are colonized by prostrate and erect algae, as well as bio-constructing animals (Ballesteros 2006). Coralligenous habitats host $20 \%$ of Mediterranean species, containing 315 algal-, 1241 invertebrate-, and 110 fish species (Ballesteros 2006).

Even though the fish fauna of adjacent ecosystems, such as infralittoral rocky reefs, sea grass meadows, and soft bottoms are well known (Reñones et al. 1997, Letourneur et al. 2001, La Mesa et al. 2011), fish fauna associated with coralligenous habitats have been given little attention due to its depth and complexity (Guidetti et al. 2002). Some studies have compiled inventories of observable fish species in this habitat (Harmelin 1990, Francour 1997, Guidetti et al. 2002, Casellato and Stefanon 2008), but to our knowledge no studies have been performed on the temporal patterning of fish behaviour in coralligenous habitats.

The majority of the studies dealing with temporal variations of fish fauna focus on annual-, seasonal-, and monthly variations (Guidetti et al. 2002, Moranta et al. 2006, Deudero et al. 2008, Condal et al. 2012, Koeck et al. 2014). At a finer temporal scale, diurnal-nocturnal shifts have been investigated in fish assemblages (Nagelkerken et al. 2000, Santos et al. 2002, Carpentieri et al. 2005, Harvey et al. 2012, Aguzzi et al. 2013) and in single species (D'Anna et al. 2011, Koeck et al. 2013). This study will focus on diurnal rhythms of fish species. Until now, diurnal rhythms have been studied in relation to abundances of fish species (Willis et al. 2006, Chabanet et al. 2012), but rhythms of different size classes within the same species have rarely been taken in account (Gries et al. 1997). Nevertheless, the study of their respective activity rhythms is important for their management and better understanding of their roles in the ecosystem (Koeller et al. 1986, Martha and Jones 2002).

The study of fish behavioural rhythms in the field requires sampling at high frequency over several consecutive $24 \mathrm{~h}$ cycles (Aguzzi and Company 2010). The monitoring by underwater video has been demonstrated as an efficient and non-destructive tool for studying fish abundance and behaviour (Fox and Bellwood 2008, Layton and Fulton 2014, Noble et al. 2014, Pink and Fulton 2015). Different video systems exist such as baited remote underwater video (BRUV) (Watson et al. 2005, Cappo et al. 2007, Lowry et al. 2012), diver operated video (DOV) (Hall and Hanlon 2002, Langlois et al. 2010), cabled video observatories (Aguzzi et al. 2013), and unbaited, remote underwater video (RUV) (Pelletier et al. 2012). The latter was used in this study to monitor the diurnal rhythms of two coastal fish species in coralligenous habitats. A labrid, the Mediterranean rainbow wrasse, Coris julis (Linnaeus, 1758), and a sparid, the common two-banded seabream, Diplodus vulgaris (Geoffroy Saint-Hilaire, 1817), were chosen for this study. Sparidae and Labridae are the dominant families in abundance and number of species in coralligenous habitats (Harmelin 1990, Guidetti et al. 2002), hence one species of each family was chosen. They are described as diurnal species (Harmelin 1987, Azzurro et al. 2007, Aguzzi et al. 2013), which are common in coralligenous habitats (Harmelin 1990, Guidetti et al. 2002) and which are easily recognizable on video samplings.

The Mediterranean rainbow wrasse, Coris julis, is a small temperate, moderately short-lived ( 2 to 4 years on average) demersal, shallow-water reef fish and is the dominant coastal wrasse in northern, shallow waters of the Mediterranean Sea. It has a sedentary lifestyle in strong association with rocky algal assemblages in sea grass beds, rocky and coralligenous habitats down to the depth of 50 m. Coris julis is known to show a clear diurnal circadian rest-activity cycle, with a migration at sunset from feeding grounds, where it spends the day, to nocturnal resting ground, where it buries itself in the sandy bottom during night-time (Videler 1986, Harmelin 1987, De Pirrott et al. 1999, Azzurro et al. 2007).

The common two-banded seabream, Diplodus vulgaris, is abundant in the sublittoral rocky bottoms down to the depth of $100 \mathrm{~m}$ (Gordoa and Molí 1997). High site fidelity was shown for this species with a home range size less than $1 \mathrm{~km}^{2}$ (Alós et al. 2012). Its activity rhythm is still under discussion. Generally characterized as a diurnal species (Aguzzi et al. 2013), other studies reveal no discernible rhythmicity (Santos et al. 2002, Alós et al. 2012, Aguzzi et al. 2013).

Both species are known as diurnal species, but knowledge is lacking on fine-scale fluctuations of abundances, considering size-classes, and behaviour throughout the diurnal period. Hence, the following questions were addressed in our study:

- Do the abundances of these two species vary during the diurnal period in coralligenous habitats?

- Are there any temporal fluctuations of abundances of different size classes within the same species?

- How does the individual behaviour of diurnal species vary during the diurnal period?

\section{MATERIAL AND METHODS}

Study areas. Two study areas of coralligenous habitats were chosen in the French Riviera (Fig. 1). They represent similar depth profiles $(0-50 \mathrm{~m})$ and the same morphology of coralligenous frameworks (rim morphology) developing on vertical cliffs (Ballesteros 2006). The coralligenous habitats of both study areas were characterized as "Lithophyllo-Halimedetum tunae" facies known to shelter an elevated species richness (mean value: 76 species $\times 10 \mathrm{~m}^{-2}$ ) (Ballesteros 2006). This facies is known to occur from a depth of $12-15 \mathrm{~m}$ to $30-35 \mathrm{~m}$ on the French Mediterranean coast (Ballesteros 2006).

The first study area is located in the marine protected area (MPA) of the Port Cros National Park (hereafter PC), at the Vessel's spit on the southeast coast off Port Cros Island (Fig. 1). The spit is a rocky spur whose east side is characterized by coralligenous habitats between depths of 30 and 45 m (Harmelin 1990). They form a narrow border limited 


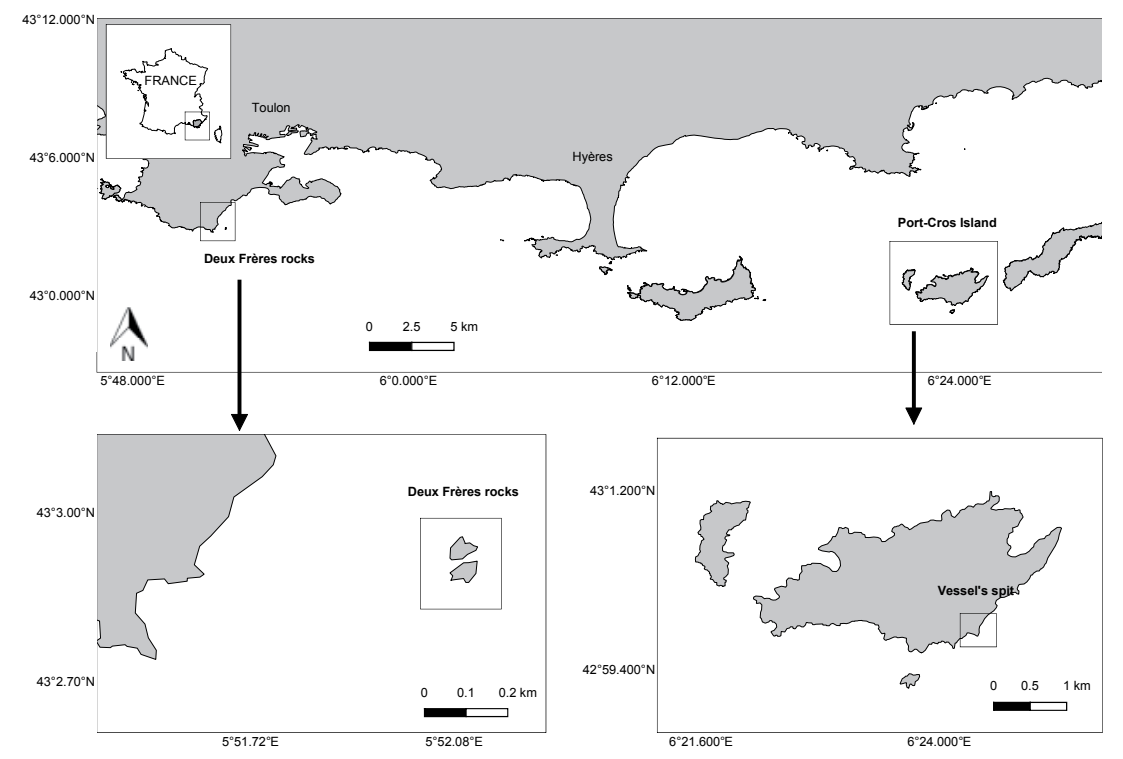

Fig. 1. Location of the two study areas: Deux Freres rocks (DF) and the Vessel's spit on Port-Cros Island (PC)

by coastal detritus sediments from the open sea. These bioconcretions are of remarkable ecological interest and are considered to be in "pristine" conservation status, with high conservation priority (Astruch et al. 2012). The protection measures for the MPA mainly concern mooring restrictions and the banning of towed fishing gears and spear fishing.

The second study area, Deux Frères (hereafter DF), belongs to the European Natura 2000 network due to its rich coralligenous habitat (Fig. 1). In contrast to $\mathrm{PC}$, there is no restriction about fishing and mooring. DF is composed of two emerging coastal rocks with a steep cliff descending to a depth of $50 \mathrm{~m}, 600 \mathrm{~m}$ off the coast. The area is characterized by a strong offshore swell and strong currents and is exposed to discharges from the "Amphitria" water treatment plant.

Sampling technique and procedure. A programmable, remote, and autonomous rotating video system was used in this study. The system was composed of a waterproof housing with a HD camera (Sony HDR-XR 520), filming in a full HD resolution of $1920 \times 1080$ pixels, a rotary motor, and a timer, which triggered the camera and the motor. A complete description of the system is given in Pelletier et al. (2012). The housing rotated by sectors of $60^{\circ}$ every $30 \mathrm{~s}$; hence a complete rotation of $360^{\circ}$ was accomplished within $3 \mathrm{~min}$. The $360^{\circ}$ view provided panoramic images, while avoiding the image distortion characteristic of fisheye lenses (Pelletier et al. 2012). For our study, the video systems were programmed to record automatically, each hour during daylight, three complete 3-min rotations during a total of 9 min without any external disturbance. Video systems were installed by divers in three stations in each study area and left in place for at least $48 \mathrm{~h}$. The number of video observations per study area was adapted to the sunset and sunrise times of the respective sampling periods:

- DF: 09:00-17:00 (sunrise: 08:07, sunset: 17:17);

- PC: 07:00-18:00 (sunrise: 07:10, sunset: 18:25).
Hours were expressed in local time (UTC $+1: 00)$.

In PC, three stations (1, 2, and 3 ) were chosen randomly and filmed in February/March 2014 (25 to 26 February and 5 to 7 March), $150 \mathrm{~m}$ off the coast of the Vessel's spit (GPS coordinates: $42^{\circ} 59.679^{\prime} \mathrm{N}, 06^{\circ} 24.473^{\prime} \mathrm{E}$ ), with interstation distances of 5-10 m, and at depths of 30 to $36 \mathrm{~m}$ (Table 1). Stations 1 and 2 were located at depths of $30 \mathrm{~m}$ and $33 \mathrm{~m}$, respectively on a sandy substrate with eroded blocs close to a large platform of bioconcretions. Station 3 was placed at a depth of $36 \mathrm{~m}$ at the foot of the platform.

Table 1

Number of hourly observation videos in the Deux Frères rocks (DF) and in the Port Cros National Park (PC), as a function of time of the day (local time; UTC + 01:00 h)

\begin{tabular}{cccccc}
\hline & $\begin{array}{c}\text { Number of videos } \\
\text { in DF }\end{array}$ & & \multicolumn{2}{c}{ Number of videos in PC } \\
\cline { 1 - 5 } Time & Station I & Station II & Station 1 & Station 2 & Station 3 \\
of day & & & & & \\
\hline Depth [m] & 27 & 37 & 30 & 33 & 36 \\
$07: 00$ & 0 & 0 & 2 & 0 & 0 \\
$08: 00$ & 0 & 0 & 2 & 2 & 1 \\
$09: 00$ & 2 & 1 & 2 & 2 & 1 \\
$10: 00$ & 2 & 2 & 2 & 2 & 1 \\
$11: 00$ & 2 & 2 & 2 & 2 & 1 \\
$12: 00$ & 3 & 2 & 3 & 2 & 1 \\
$13: 00$ & 3 & 2 & 2 & 2 & 2 \\
$14: 00$ & 3 & 2 & 2 & 2 & 2 \\
$15: 00$ & 3 & 2 & 2 & 2 & 2 \\
$16: 00$ & 3 & 2 & 2 & 2 & 2 \\
$17: 00$ & 3 & 1 & 2 & 2 & 2 \\
$18: 00$ & 0 & 0 & 2 & 2 & 0 \\
Total & 24 & 16 & 25 & 22 & 15 \\
\hline
\end{tabular}

In DF, three randomly chosen stations (I, II, and III) were filmed from 7 through 9 January 2014, $70 \mathrm{~m}$ 
off the south-eastern tip of the rocks (GPS coordinates: $43^{\circ} 02.684^{\prime} \mathrm{N}, 05^{\circ} 52.155^{\prime \prime} \mathrm{E}$ ) (Table 1). Station I was placed at a depth of $27 \mathrm{~m}$ on a small rocky platform composed of big rocks, facing a steep cliff with bioconcretions, covered with erected species, such as gorgonians (Eunicella spp., Paramuricea clavata). Station II was located $10 \mathrm{~m}$ below the first one (depth of $37 \mathrm{~m}$ ), at the foot of this steep cliff. Station III was placed at an intermediate depth of $33 \mathrm{~m}$ on a sandy patch in a fault between two cliffs of bioconcretions. Unfortunately, the camera in station III did not record due to an unexpected technical problem, hence only stations I and II were exploited in DF.

The number of hourly observation videos by station is detailed in Table 1. In DF, the first observation took place at 12:00 in station I on the first day and at 10:00 on the second day in station II (7-9 Jan 2014). In PC, for the first period, the camera started filming at 13:00 in station 3 (25-26 Feb 2014). For the second period (5-7 Mar 2015), observations started at 12:00 in station 1, and at 13:00 in station 2 on the same day.

Analysis of observation videos. For each hourly observation video, individuals of Coris julis and Diplodus vulgaris were identified and quantified by a single observer according to the procedure explained in Pelletier et al. (2012). Individuals were counted per sector and then summed over the six sectors of a rotation of $360^{\circ}$. The mean abundance over rotations was calculated to average out the variability between rotations (Pelletier et al. 2012).

To minimize potential double counting, the direction of fish movement and camera rotation were taken into account.
Nevertheless, recounting errors persist regardless the monitoring tool, and are considered as proportional upon the rate of swimming activity of individuals (Aguzzi et al. 2010). Moreover, individual sizes were determined relative to three size-classes (small, medium, and large). Their size bounds corresponded to $1 / 3$ and $2 / 3$ of the maximum total length observed for individuals observed in the Mediterranean Sea (Coris julis: small: $<8 \mathrm{~cm}$, medium: $8-16 \mathrm{~cm}$, large: $>16 \mathrm{~cm}$; Diplodus vulgaris: small: $<11 \mathrm{~cm}$, medium: $11-23$ $\mathrm{cm}$, large: $>23 \mathrm{~cm}$ ). The observer was trained to estimate individual sizes with a database of screenshots of plastic fish silhouettes of different colours (bright and dark ones), known sizes $(0.2 \mathrm{~m}, 0.4 \mathrm{~m}, 0.6 \mathrm{~m}, 0.8 \mathrm{~m}$, and $1 \mathrm{~m})$ and known distances from the same camera $(2 \mathrm{~m}, 5 \mathrm{~m}, 7 \mathrm{~m}$, and $10 \mathrm{~m}$ ) (Mallet et al. 2014). In addition, the behaviour of each individual of $C$. julis and $D$. vulgaris was analysed according to the behavioural categories defined in Table 2, based on definitions of quantification of fish behaviour in Fulton and Bellwood (2002) and Milazzo et al. (2013).

In all, 102 exploitable videos were analysed, with 40 videos in DF (360 min in total) and 62 videos in PC (558 min in total). The time of analysis per hourly observation video ranged from 30 to $45 \mathrm{~min}$. Therefore, $456 \mathrm{~h}$ were necessary for the complete analysis of all videos.

Statistical analysis. Abundances in numbers of individuals per count (hereafter ind. $\cdot$ count $^{-1}$ ) and mean percentages of individuals per behavioural category were calculated for Coris julis and Diplodus vulgaris separately over the three rotations of each hourly observation video. To avoid pseudo-replication over consecutive sampling

Table 2

The behaviours observed and their associated categories and definitions determined for each individual of Coris julis and Diplodus vulgaris

\begin{tabular}{|c|c|c|}
\hline Behaviour & Category & Definition \\
\hline \multirow[t]{2}{*}{ Main individual activity } & Feeding & $\begin{array}{l}\text { The individual is observed feeding, the head is inclined towards the substratum } \\
\text { and the jaws are in contact with or above the substratum/prey }\end{array}$ \\
\hline & $\begin{array}{l}\text { Travelling or other } \\
\text { activities }\end{array}$ & $\begin{array}{l}\text { The individual is observed to be travelling with its body parallel and moving } \\
\text { forward with the head first relative to the substratum or to be searching with its } \\
\text { head inclined towards the substratum/prey. The individual can also be observed } \\
\text { resting }\end{array}$ \\
\hline \multirow{3}{*}{$\begin{array}{l}\text { Intraspecific social } \\
\text { behaviour }\end{array}$} & Solitary & The individual is observed without any conspecifics \\
\hline & Small group & $\begin{array}{l}\text { Individuals form small groups with conspecifics of the same species ( } 2-10 \\
\text { individuals), where individuals either show the same or different main } \\
\text { individual activities }\end{array}$ \\
\hline & Gregarious & $\begin{array}{l}\text { Individuals are observed in groups ( }>10 \text { individuals) with a schooling } \\
\text { behaviour, sharing the same activity }\end{array}$ \\
\hline \multirow[t]{2}{*}{ Mobility } & Mobile & $\begin{array}{l}\text { The individual is only observed for a few seconds crossing the camera's field } \\
\text { of view at a constant swimming speed and seems to travel (body parallel and } \\
\text { moving forward head first relative to the substratum) }\end{array}$ \\
\hline & Sedentary & $\begin{array}{l}\text { The individual is constantly observed in the camera's field of view without a } \\
\text { travelling behaviour, and seems to feed, search or be stationary with the body } \\
\text { parallel and static near or above the substratum, with or without moving fins }\end{array}$ \\
\hline
\end{tabular}

Definitions of the categories of main individual activities are defined based on the work of Fulton and Bellwood (2002) and Milazzo et al. (2013). 
days for a station, abundance and behaviour data was averaged over the sampling days for a given time of day and each station.

For each species, differences in abundances (either grouped or by size class) and differences in behaviours were investigated according to the hour (9 levels in DF from 09:00 to 17:00, 12 levels in PC from 07:00 to 18:00) and the station (2 levels in DF, 3 levels in PC). Therefore, two-way PERMANOVAs were performed. Indeed, this method allows the handling of complex, unbalanced and multiple factors design and does not assume a normal distribution of errors (Anderson 2001). The "time of the day" factor was treated as fixed and the "station" factor as random (Anderson 2001). Abundance data was $\log (x+1)$ transformed before the generation of Euclidean distance similarity matrixes. For the behaviour data, the Bray-Curtis measure of similarity was used. $P$-values were calculated with 9999 random permutations of residuals under a reduced model and Type III sum of square (Anderson 2001). Significance was set at $\boldsymbol{\alpha}=$ 0.05 . The lack of replicates due to the averaging of data over consecutive sampling days was integrated in the PERMANOVA analysis by excluding the highest-order interaction term, as suggested by Clarke and Warwick (2001). All these analysis were performed using the PRIMER 6 software and the PERMANOVA add-on (Clarke and Warwick 2001).

\section{RESULTS}

Individuals of Coris julis were observed in $100 \%$ of the videos in the two areas, whereas Diplodus vulgaris was identified in $95 \%$ of the videos in PC and in $100 \%$ of the videos in DF. Considering data from the two study areas, different individual behaviours and the three size classes could be observed for both species. However, very few small $C$. julis were observed in DF (mean value: $0.1 \pm 0.3$ $(\mathrm{SE})$ ind. $\cdot$ count $\left.^{-1}\right)$, compared to $5.5 \pm 7.8$ (SE) small ind.
. count ${ }^{-1}$ in PC. In contrast, no small $D$. vulgaris were observed in PC, whereas they were present in DF.

Temporal patterning and spatial variations of abundances. The global fish abundances per count varied between species and study areas: in DF, mean value $10.3 \pm 5.4(\mathrm{SE})$ ind. $\cdot$ count $^{-1}$ of Coris julis and $4.7 \pm 5.8$ (SE) ind. ' count ${ }^{-1}$ of Diplodus vulgaris were observed, whereas these figures reached respectively $25.6 \pm 19.2$ (SE) and $2.4 \pm 2.3$ (SE) ind. $\cdot$ count $^{-1}$ in PC.

Spatio-temporal activity rhythms varied greatly between species and study areas (Figs. 2-4). In $\mathrm{PC}$, grouped abundances per count of $C$. julis varied significantly during the diurnal period (Table 3), with few individuals in crepuscular periods and highest abundances in the morning and in the afternoon (Fig. 2). These differences were mainly due to significant diurnal variations in abundances of small and medium C. julis (Table 4). Indeed, similar temporal patterning was observed for these size classes: their abundances were low at 07:00, highest in the afternoon, and decreased sharply in the evening (18:00) (Fig. 3). In contrast, although not significant, the abundances of large-sized individuals increased at the end of the day in PC (Fig. 3). In DF, no significant temporal variation of the abundances of $C$. julis was observed, whether considering size classes grouped or not (Tables 3 and 4, Figs. 2-4). Similarly, whatever the study area, mean abundances per count of $D$. vulgaris did not present significant diurnal variations as a function of the hour (Tables 3 and 4, Figs. 2-4).

Besides temporal variations of abundances, significant spatial variations of mean abundances per count were observed for the size classes of $C$. julis (except for small and large individuals in DF), and D. vulgaris (except for large ones in PC) (Table 4). This result is also true when size classes are considered grouped (Table 3 ). For the two species, lowest mean abundances per count were observed in the deepest stations (PC-3 and DF-II).

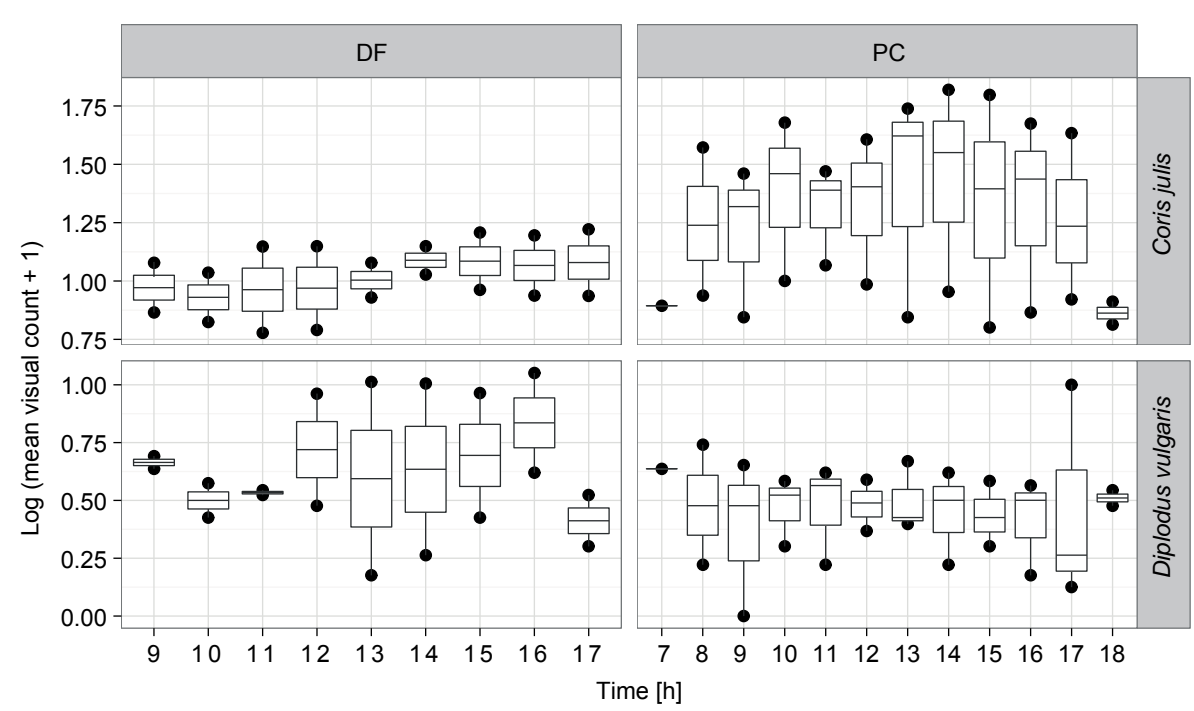

Fig. 2. Diurnal patterning of mean visual counts of total abundances of Coris julis and of Diplodus vulgaris in the DeuxFrères rocks (DF) and in Port-Cros Island (PC) 


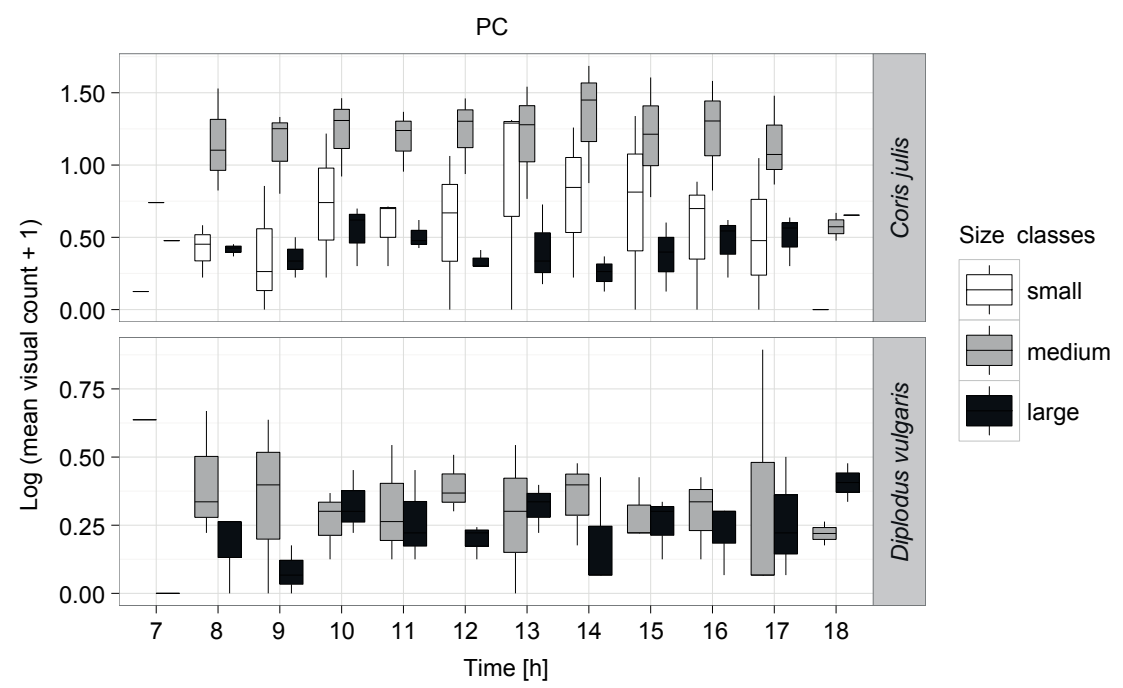

Fig. 3. Diurnal patterning of mean visual counts of the size classes (small, medium, large) of Coris julis and of Diplodus vulgaris in Port-Cros Island (PC)

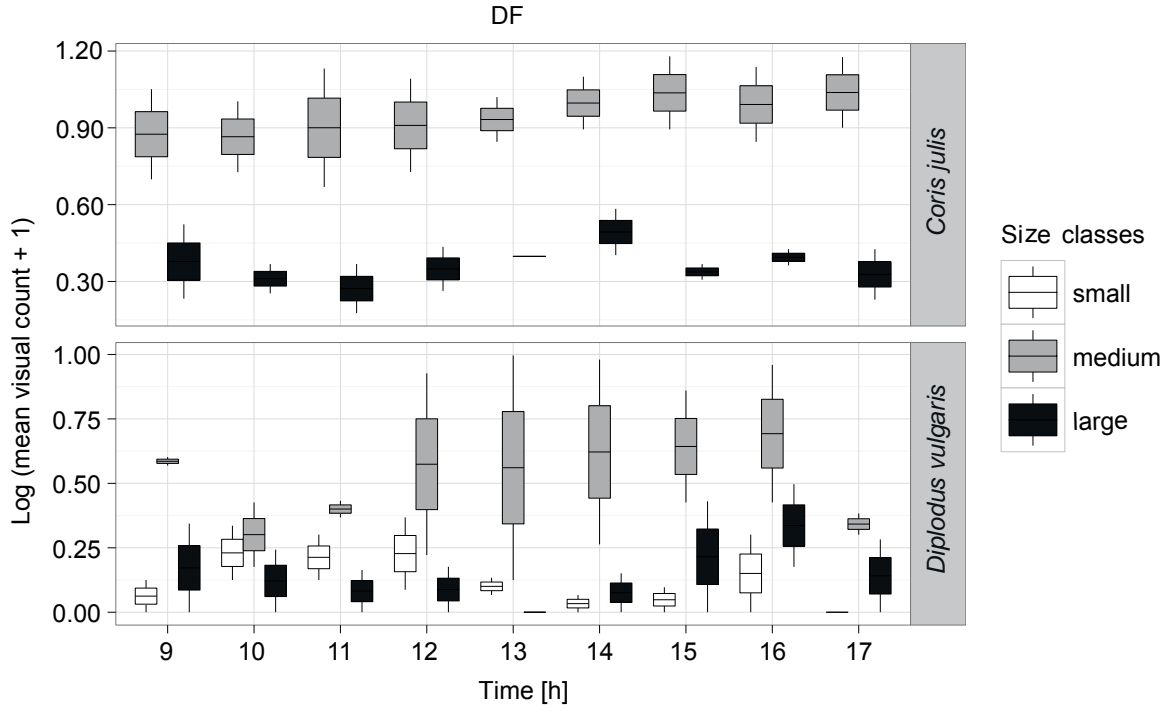

Fig. 4. Diurnal patterning of mean visual counts of the size classes (small, medium, large) of Coris julis and of Diplodus vulgaris in the Deux-Frères rocks (DF)

Temporal patterning and spatial variations of individual behaviour. Spatio-temporal changes in the three different behavioural types showed major variations between species and study areas (Figs. 5 and 6). Even though behavioural data should be interpreted with caution, some general temporal and spatial trends could still be discerned. Although differences were not significant in PC (Table 5), the main activity of Coris julis and Diplodus vulgaris changed between the morning (08:00-12:00) and crepuscular periods (07:00, 17:00-18:00) (Fig. 5).

During the morning (08:00-12:00), feeding was the main activity of the two species in both study areas, whereas this activity decreased during the crepuscular period (18:00), except for D. vulgaris in DF (Figs. 5 and 6). Moreover, feeding climaxes differed between the two species. In PC, the majority of $C$. julis was feeding at 09:00, whereas the feeding climax of $D$. vulgaris was at midday (Fig. 5).
Regarding intraspecific social behaviour (solitary individuals or small groups), significant temporal differences were found for C. julis in PC (Table 5). Whereas the majority of $C$. julis formed small groups during the day, a major part of solitary individuals was observed during crepuscular periods (07:00, 18:00) (Fig. 5 ). Even though not statistically significant, the opposite social behaviour was observed for C. julis in DF with a sudden increase of grouped individuals at 17:00 (Fig. 6).

Opposite patterns of the social behaviour were observed for D. vulgaris between DF and PC. Whereas the majority of individuals were observed solitary at the end of the day in DF (17:00), the opposite was true for PC (18:00) (Figs. 5 and 6).

Moreover, significant temporal differences of mobility/ sedentarity behaviour were found for C. julis in PC (Table 5). Whereas the majority of individuals were observed to be 
Table 3

PERMANOVA comparing the mean visual counts per hour of Coris julis and Diplodus vulgaris as a function of the time of the day and the station

\begin{tabular}{|c|c|c|c|c|c|c|c|c|c|c|}
\hline & \multirow[b]{2}{*}{ Source } & \multirow[b]{2}{*}{$\mathrm{df}$} & \multicolumn{4}{|c|}{ Coris julis } & \multicolumn{4}{|c|}{ Diplodus vulgaris } \\
\hline & & & MS & Pseudo-F & $P($ perm $)$ & Permut. & MS & Pseudo-F & $P($ perm $)$ & Permut. \\
\hline \multirow[t]{4}{*}{ PC } & Time & 11 & 0.65 & 9.39 & 0.0006 & 9951 & 0.02 & 0.16 & 0.9980 & 9951 \\
\hline & Station & 2 & 7.06 & 101.61 & 0.0001 & 9948 & 2.09 & 17.21 & 0.0001 & 9951 \\
\hline & Res. & 19 & 0.07 & & & & 0.12 & & & \\
\hline & Total & 32 & & & & & & & & \\
\hline \multirow[t]{4}{*}{ DF } & Time & 8 & 0.04 & 0.41 & 0.8846 & 9937 & 0.17 & 0.75 & 0.6537 & 9953 \\
\hline & Station & 1 & 0.79 & 7.95 & 0.0270 & 9862 & 3.56 & 15.57 & 0.0048 & 9850 \\
\hline & Res. & 8 & 0.10 & & & & 0.23 & & & \\
\hline & Total & 17 & & & & & & & & \\
\hline
\end{tabular}

Bold print indicates statistical significance $(P<0.05) ; \mathrm{PC}=$ Port Cros National Park, $\mathrm{DF}=$ Deux Frères rocks, $\mathrm{df}=$ degrees of freedom, $\mathrm{MS}=$ mean squares, Pseudo- $\mathrm{F}=\mathrm{F}$ value by permutation, $P($ perm $)=$ permutation $P$-value, Permut. $=$ number of random permutations.

Table 4

PERMANOVA analysing mean visual counts per hour of each size classes of Coris julis and of Diplodus vulgaris as a function of the time of the day and the station

\begin{tabular}{|c|c|c|c|c|c|c|c|c|}
\hline & \multirow[b]{2}{*}{ Source } & \multirow[b]{2}{*}{ df } & \multicolumn{3}{|c|}{ Coris julis } & \multicolumn{3}{|c|}{ Diplodus vulgaris } \\
\hline & & & Small & Medium & Large & Small & Medium & Large \\
\hline \multirow[t]{2}{*}{ PC } & Time & 11 & 0.0013 & 0.0009 & 0.0915 & NA & 0.7301 & 0.2272 \\
\hline & Station & 2 & 0.0001 & 0.0001 & 0.0002 & NA & 0.0001 & 0.0278 \\
\hline \multirow[t]{2}{*}{$\mathrm{DF}$} & Time & 8 & NA & 0.8884 & 0.5548 & 0.3551 & 0.6594 & 0.1181 \\
\hline & Station & 1 & NA & 0.0121 & 0.0558 & 0.1023 & 0.0066 & 0.0009 \\
\hline
\end{tabular}

Bold print indicates statistical significance $(P<0.05) ; \mathrm{PC}=$ Port Cros National Park, $\mathrm{DF}=$ Deux Frères rocks; $\mathrm{df}=$ degrees of freedom.

sedentary during the day (07:00-17:00), the majority were mobile at 18:00 (Fig. 5). Even though not statistically significant, the same increase in mobility was observed for D. vulgaris in PC at 18:00 (Fig. 5) and for both species in the DF area at 17:00 (Fig. 6). Hence, the increase in mobility in crepuscular periods is consistent between species in both study areas, but observed in a lesser degree in DF.

At the scale of the study area, significant spatial variations in fish behaviour were observed (Table 5). The main activity showed significant spatial variations for both species, but only in the DF study area (Table 5). Significant differences of social behavioural categories were observed between stations within both study areas and for both species, except for D. vulgaris in PC (Table 5). In addition, there were significant differences in mobility and sedentarity between stations for C. julis in PC (Table 5).

\section{DISCUSSION}

The presently reported study provided a "snapshot" of the activity rhythms of two common and abundant Mediterranean diurnal fish species in coralligenous habitats. Underwater video systems allowed obtaining temporal, high frequency data on fish abundances and behaviour in high-relief, deep-water habitats. It would have been difficult to obtain similar data during several consecutive days with the same scuba diver. Moreover, the static and discrete video system has been outlined as an appropriate tool for the study of fish behaviour, due to its low disturbance compared to divers, whose presence can induce changes of fish behaviour (Chapman et al. 1974, Hannah and Blume 2012, Mallet et al. 2014).

Temporal patterning of abundances and behaviours. In habitats with high structural complexity, such as coralligenous habitats, high species richness is the usual response of fish communities, resulting in an increase in temporal partitioning of species (Letourneur et al. 2001). Our results highlighted temporal variability of the two fish species analysed, regarding abundances and behaviour as a function of the hour during the daylight period.

Intra-diel variations of density estimates have already been observed during daylight hours (Azzurro et al. 2013). A bell-shaped pattern is generally expected for diurnal species, with an anticipated decline early and late in the day and a peak of abundances at midday (Spyker and Van Den Berghe 1995, Santos et al. 2002, Aguzzi et al. 2013). Our results partially confirmed this for Coris julis, since very few individuals were observed in the beginning and end of the day in PC, whereas abundances peaked in the beginning of the afternoon. For Diplodus vulgaris, no significant diurnal pattern in abundances was observed in both study areas. These results do support those from other studies, which revealed no discernible rhythmicity of abundances of $D$. vulgaris due to highly variable detections (Santos et al. 2002, Alós et al. 2012, Aguzzi et al. 2013). 


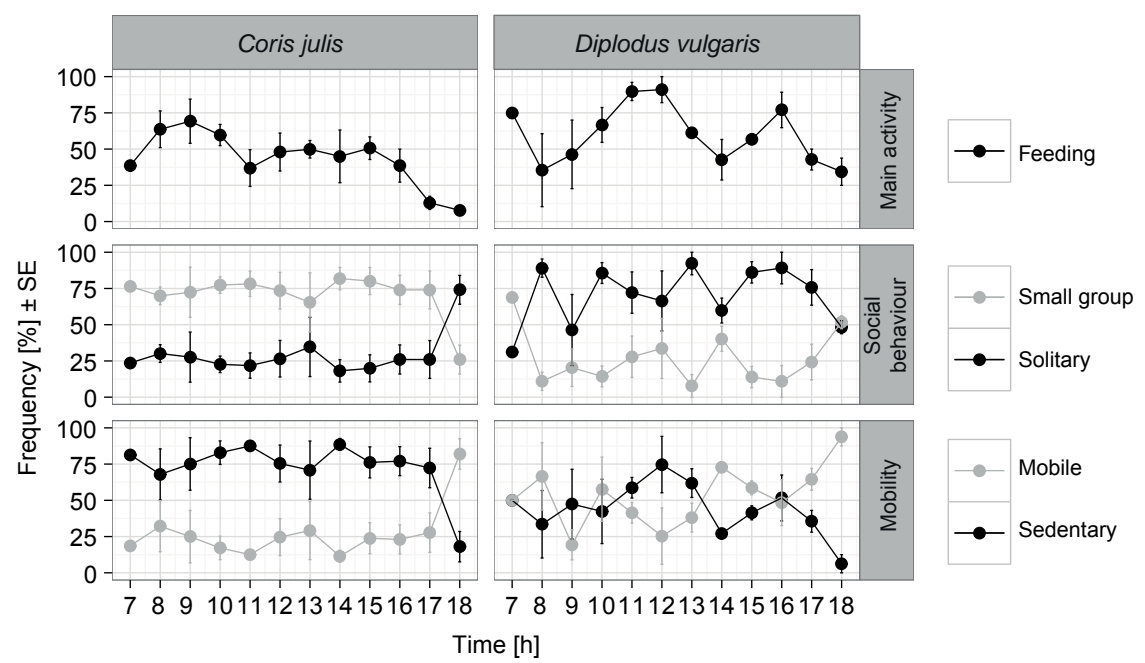

Fig. 5. Diurnal patterning of the mean percentage of individuals regarding main activity, intraspecific social behaviour and mobility/sedentarity of Coris julis and Diplodus vulgaris in Port-Cros Island

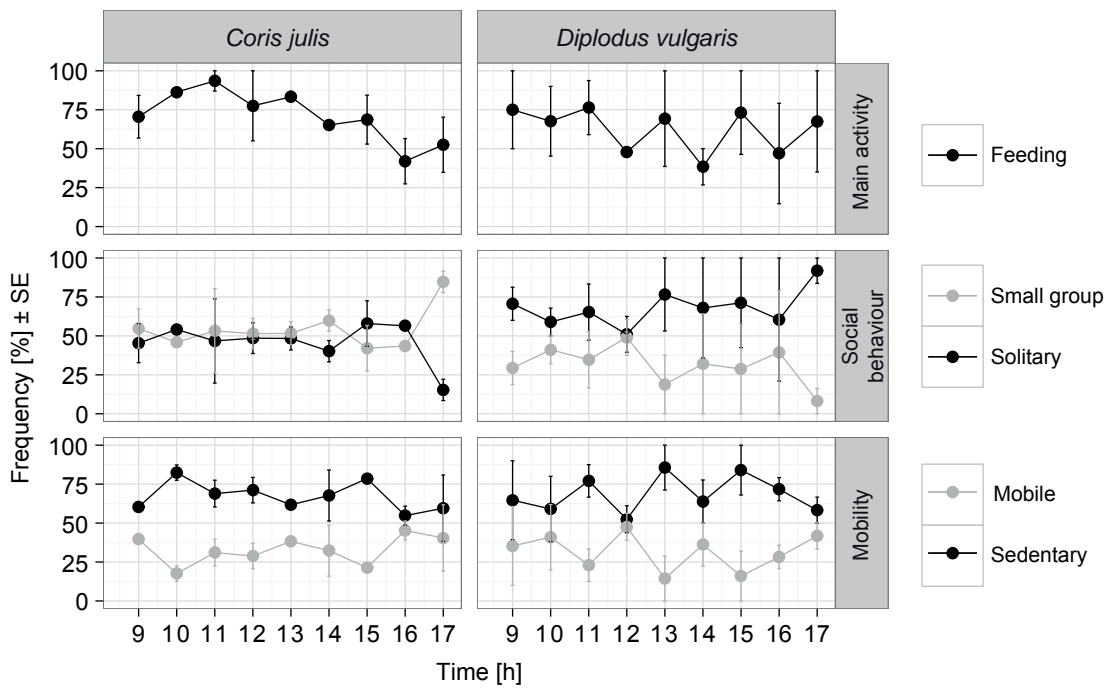

Fig. 6. Diurnal patterning of the mean percentage of individuals regarding main activity, intraspecific social behaviour and mobility/sedentarity of Coris julis and Diplodus vulgaris in the Deux-Frères rocks

Table 5

PERMANOVA comparing mean percentages per hour of individuals of the behavioural categories of the three analysed behaviours of Coris julis and of Diplodus vulgaris as a function of the time of the day and the station

\begin{tabular}{clcccccccc}
\hline & & \multicolumn{3}{c}{ Coris julis } & & \multicolumn{3}{c}{ Diplodus vulgaris } \\
\cline { 8 - 10 } \cline { 6 - 9 } & Source & MA & SB & MS & & MA & SB & MS \\
\hline \multirow{2}{*}{ PC } & Time & 0.0678 & $\mathbf{0 . 0 1 3 4}$ & $\mathbf{0 . 0 0 0 9}$ & & 0.0596 & 0.2078 & 0.2164 \\
& Station & 0.8847 & $\mathbf{0 . 0 0 0 1}$ & $\mathbf{0 . 0 0 0 1}$ & & 0.4836 & 0.0975 & 0.4438 \\
& Time & 0.0786 & 0.2002 & 0.6751 & & 0.2156 & 0.8415 & 0.5929 \\
& Station & 0.0111 & $\mathbf{0 . 0 3 7 6}$ & 0.9860 & & $\mathbf{0 . 0 0 0 5}$ & 0.0295 & 0.0695 \\
\hline
\end{tabular}

Bold print indicates statistical significance $(P<0.05)$; $\mathrm{MA}=$ main individual activity, $\mathrm{SB}=$ intraspecific social behaviour, $\mathrm{MS}=$ mobility/ sedentarity; $\mathrm{PC}=$ Port Cros National Park, $\mathrm{DF}=$ Deux Frères rocks. 
Looking at both species, their abundances did not present the same temporal patterning, even though both are considered as diurnal. These results are in agreement with previous studies highlighting that diurnal species patterns are much more diverse than anticipated; there is no "standard" pattern of diurnal variation among the species (Colton and Alevizon 1981, Spyker and Van Den Berghe 1995). With regards to behaviours, preferential feeding hours were revealed for $C$. julis. The foraging behaviour is generally considered to be restricted to the period of the day when food is abundant, the presence of predators is reduced and the mortality/food intake rate is minimized (Clark and Levy 1988, López-Olmeda et al. 2006). In our study, feeding of $C$. julis occurred mainly in the morning in PC, whereas the percentage of feeding animals decreased progressively in the afternoon. The morning possibly represents the optimal foraging period regarding prey availability/quality and predation risk for Coris julis. Our results were consistent with the feeding patterns of C. julis described by De Pirrott et al. (1999): a burst of foraging activity at dawn, followed by a plateau during the central part of the day and a linear decrease before dusk. In our study, different feeding patterns of $C$. julis were observed between the two study areas. In contrast to PC, abundances of feeding $C$. julis also peaked in the afternoon in DF, not only in the morning. According to a hypothesis made by De Pirrott et al. (1999), this feeding pattern with two peaks in the morning and in the beginning if the afternoon could correspond to an increase in relative food availability. Hence, differences in prey availability in the different study areas could possibly provoke variations of feeding patterns. In contrast, Diplodus vulgaris showed several peaks of abundances of feeding animals during the day; leading to the conclusion that feeding potentially occurs at any time of the day for this species. This result is in agreement with Alos et al. (2012), which outlined no diel-time preference for feeding of $D$. vulgaris.

Moreover, this study revealed a sudden change of the mobility/sedentarity and the intra-specific social behaviour of both species at the end of the day, when fish became more mobile and more solitary. Twilight periods and associated changes of behaviour in fishes have been the subject of numerous studies (Hobson 1972, 1973). During the transition period between daylight and darkness, species exhibit a changeover from diurnal activities to nocturnal activities, with migrations between diurnal feeding and nocturnal sheltering grounds (Hobson 1972, Nagelkerken et al. 2000). Changes in mobility and social behaviour as observed in our study might be explained by activity changes and migrations in crepuscular periods. Nevertheless, these are preliminary results to be interpreted with caution and to be completed by future studies. Variations in abundances, as in our study, do indicate changes in activity patterns at each station or study area, but do not show if animals were not active at other sites of this habitat or in nocturnal periods. Unfortunately, data and understanding could not be completed with samplings in nocturnal periods, since the video systems used in this study are not designed to be used by night.
Temporal segregation between size classes. The majority of studies on diurnal rhythms focus on variations in species abundances without considering life history stages (Spyker and Van Den Berghe 1995, Willis et al. 2006). However, taking into account abundance variations of different size classes provides additional elements that give better understanding of the patterns observed. Our results stress that diurnal patterning is not only different between species, but also among conspecifics of different life stages, represented by different size classes. For instance, abundances of small and medium sized Coris julis were low in crepuscular periods, whereas large-sized individuals were equally abundant during the day. Diel activity partitioning has already been reported for Atlantic salmon, Salmo salar Linnaeus, 1758, with post-young-of-the-year exhibiting mainly nocturnal activity, while young-of-the-year were observed during both day and night (Spyker and Van Den Berghe 1995, Willis et al. 2006). Regarding D. vulgaris, even though not significant, an increasing abundance of large-sized individuals was observed at the end of the day in PC, which is in agreement with observations from Azzurro et al. (2007), showing a size distribution skewed toward large individuals during the night time. Indeed, crepuscular periods represent a less favourable period for diurnal individuals, whose vision is not adapted to dim light conditions. This especially concerns young and smallsized individuals, which are exposed to a greater predation pressure than older and bigger fish (Helfman 1981, Gibson et al. 1998). An increased activity of larger and older individuals later in the evening compared to smaller fish could also be related to a diet shift, as observed in lakes (Helfman 1981). Consequently, variability in abundances of different life stages at different times of day should be taken into account for population assessments and spatial comparisons.

Spatial variations of abundances and behaviours. Apart from temporal variations in abundances and fish behaviour, spatial differences in patterns of abundances and behaviour were found:

- At large scale between the two study areas, and

- At the smallest spatial scale between stations within a study area.

At the larger spatial scale, it has to be outlined that the sampling design does not allow the pooling of data of both study areas, since they were sampled in different periods (sampling was spaced over 2 months), showed different hydrodynamic conditions and were exposed to different anthropogenic pressures.

We expected to observe similar general diurnal patterns of abundances and behaviour, despite these differences between the study areas, which was not the case. Even though both study areas consisted of the same habitat of bioconcretions, only PC presented temporal differences in abundances, size classes and behaviour for the two species analysed. No rhythmic patterns were found in the DF study area. In general, diel patterns are more often observed in stable benthic environments, with stable hydrological conditions (Guidetti et al. 2002), than in habitats with 
high hydrological instability (Letourneur et al. 2001). The DF study area is characterized by strong hydrodynamic conditions (strong off-shore swell and currents), compared to more stable conditions in $\mathrm{PC}$, minimizing effects on movement and behaviour (Guidetti et al. 2002). Hence differences in hydrodynamic conditions could explain the fact that diurnal abundances and behaviour rhythms were only revealed in PC.

Differences in fishing pressure could also represent a possible factor responsible for observed differences. Fishing is a non-predictable form of predation and could cause a shift in fish behaviour, such as the disruption of diurnal movement patterns or different feeding periods.

The small-scale variability in abundances and fish behaviour highlighted between stations within a study area can be explained by the availability of microhabitats found in coralligenous habitats. Indeed, the coralligenous habitats of the north-western Mediterranean Sea are known to display very similar biodiversity patterns at site and locality scale (Piazzi et al. 2009, Casas-Güell et al. 2015), whereas the greatest variability is found at the scale of the station, linked to the heterogeneity of the substrate and its microhabitats (Balata et al. 2005, Piazzi et al. 2009, Casas-Güell et al. 2015).

Conclusions. Our study confirmed the use of videoimaging as an efficient non-destructive tool for the study of fish fauna in structurally complex, highly valuable habitats. Video-imaging should be considered as a valuable tool for coastal monitoring of fishes in the actual context of increasing anthropogenic pressures.

Moreover, the study provided preliminary insights into diurnal variations of abundances of different life stages and of fish behaviour of two species, which have rarely been studied in the field. Fine-scale diurnal patterns could be examined in depth in other habitats and for other species. Understanding the natural activity rhythms of fish species could be the first step in assessing possible modifications of activity rhythms in response to changing environmental conditions. Finally, variability in abundances of life stages and of fish behaviours at different times of day should be taken into account for population assessments and spatial comparisons.

\section{ACKNOWLEDGEMENTS}

This survey was funded by the French Institute for the Exploration of the Sea (Ifremer) within the VIDEOBIOMED project. We are grateful to the Port-Cros National Park for its technical assistance and permission to enter and film in the protected area. We also thank Stéphane Sartoretto, Benoit Devoïgt, Christophe Ravel, and Fabienne Chavanon from Ifremer for the technical production of this study.

\section{REFERENCES}

Aguzzi J., Company J.B. 2010. [Chapter three] Chronobiology of deep-water decapod crustaceans on continental margins. Advances in Marine Biology 58: 155-225.

DOI: 10.1016/B978-0-12-381015-1.00003-4
Aguzzi J., Costa C., Furushima Y., Chiesa J.J., Company J.B., Menesatti P., Iwase R., Fujiwara Y. 2010. Behavioral rhythms of hydrocarbon seep fauna in relation to internal tides. Marine Ecology Progress Series 418: 47-56.

DOI: $10.3354 /$ meps08835

Aguzzi J., Sbragaglia V., Santamaría G., Del Río J., Sardà F., Nogueras M., Mànuel A. 2013. Daily activity rhythms in temperate coastal fishes: Insights from cabled observatory video monitoring. Marine Ecology Progress Series 486: 223-236.

DOI: $10.3354 /$ meps 10399

Alós J., Cabanellas-Reboredo M., March D. 2012. Spatial and temporal patterns in the movement of adult two-banded sea bream Diplodus vulgaris (SaintHilaire, 1817). Fisheries Research 115-116: 82-88. DOI: 10.1016/j.fishres.2011.11.025

Anderson M.J. 2001. A new method for non-parametric multivariate analysis of variance. Austral Ecology 26 (1): 32-46. DOI: 10.1111/j.1442-9993.2001.01070.pp.x

Astruch P., Boudouresque C.F., Bonhomme D., Goujard A., Antonioli P.-A., Bonhomme P., Perez T., Ruitton S., De Saint-Martin T., Verlaque M. 2012. Mapping and state of conservation of benthic marine habitats and assemblages of Port-Cros national Park (Provence, France, northwestern Mediterranean Sea). Scientific Reports of Port-Cros National Park 26: 45-90.

Azzurro E., Aguzzi J., Maynou F., Chiesa J.J., Savini D. 2013. Diel rhythms in shallow Mediterranean rockyreef fishes: A chronobiological approach with the help of trained volunteers. Journal of the Marine Biological Association of the United Kingdom 93 (2): 461-470. DOI: $10.1017 / \mathrm{S} 0025315412001166$

Azzurro E., Pais A., Consoli P., Andaloro F. 2007. Evaluating day-night changes in shallow Mediterranean rocky reef fish assemblages by visual census. Marine Biology 151 (6): 2245-2253. DOI: $10.1007 / \mathrm{s} 00227-007-0661-9$

Balata D., Piazzi L., Cecchi E., Cinelli F. 2005. Variability of Mediterranean coralligenous assemblages subject to local variation in sediment deposition. Marine Environmental Research 60 (4): 403-421. DOI: 10.1016/j.marenvres.2004.12.005

Ballesteros E. 2006. [4] Mediterranean coralligenous assemblages: A synthesis of present knowledge. Pp. 123-195. In: Gibson R.N., Atkinson R.J.A., Gordon J.D.M. (eds.) Oceanography and Marine Biology: An Annual Review, Vol. 44. CRC Press (Taylor and Francis Group), Boca Raton, FL, USA.

Bégout Anras M.-L., Lagardére J.-P., Lafaye J.-Y. 1997. Diel activity rhythm of seabass tracked in a natural environment: Group effects on swimming patterns and amplitudes. Canadian Journal of Fisheries and Aquatic Sciences 54 (1): 162-168.

DOI: $10.1139 / \mathrm{f} 96-253$

Cappo M., De'ath G., Speare P. 2007. Inter-reef vertebrate communities of the Great Barrier Reef Marine Park 
determined by baited remote underwater video stations. Marine Ecology Progress Series 350: 209-221.

DOI: $10.3354 /$ meps07189

Carpentieri P., Colloca F., Ardizzone G.D. 2005. Daynight variations in the demersal nekton assemblage on the Mediterranean shelf-break. Estuarine, Coastal and Shelf Science 63 (4): 577-588.

DOI: $10.1016 /$ j.ecss.2005.01.005

Casas-Güell E., Teixidó N., Garrabou J., Cebrian E. 2015. Structure and biodiversity of coralligenous assemblages over broad spatial and temporal scales. Marine Biology 162 (4): 901-912. DOI: $10.1007 / \mathrm{s} 00227-015-2635-7$

Casellato S., Stefanon A. 2008. Coralligenous habitat in the northern Adriatic Sea: An overview. Marine Ecology 29 (3): 321-341.

DOI: $10.1111 / \mathrm{j} .1439-0485.2008 .00236 . x$

Chabanet P., Loiseau N., Join J.-L., Ponton D. 2012. VideoSolo, an autonomous video system for highfrequency monitoring of aquatic biota, applied to coral reef fishes in the Glorioso Islands (SWIO). Journal of Experimental Marine Biology and Ecology 430-431: 10-16.

DOI: 10.1016/j.jembe.2012.06.024

Chapman C.J., Johnstone A.D.F., Dunn J.R., Creasey D.J. 1974. Reactions of fish to sound generated by divers' open-circuit underwater breathing apparatus. Marine Biology 27 (4): 357-366.

DOI: $10.1007 / \mathrm{BF} 00394372$

Clark C.W., Levy D.A. 1988. Diel vertical migrations by juvenile sockeye salmon and the antipredation window. American Naturalist 131 (2): 271-290.

DOI: $10.1086 / 284789$

Clarke K.R., Warwick R.M. 2001. Change in marine communities: an approach to statistical analysis and interpretation. 2nd edn. Primer-E Ltd, Plymouth Marine Laboratory, Plymouth, UK.

Colton D.E., Alevizon W.S. 1981. Diurnal variability in a fish assemblage of a Bahamian coral reef. Environmental Biology of Fishes 6 (3): 341-345. DOI: $10.1007 / \mathrm{BF} 00005762$

Condal F., Aguzzi J., Sardà F., Nogueras M., Cadena J., Costa C., Del Río J., Mànuel A. 2012. Seasonal rhythm in a Mediterranean coastal fish community as monitored by a cabled observatory. Marine Biology 159 (12): 2809-2817.

DOI: $10.1007 / \mathrm{s} 00227-012-2041-3$

D’Anna G., Giacalone V.M., Pipitone C., Badalamenti F. 2011. Movement pattern of white seabream, Diplodus sargus (L., 1758) (Osteichthyes, Sparidae) acoustically tracked in an artificial reef area. Italian Journal of Zoology 78 (2): 255-263. DOI: $10.1080 / 11250000903464059$

De Pirrott M., Marchetti G.M., Chelazzi G. 1999. Foraging interactions among three benthic fish in a Posidonia oceanica reef lagoon along the Tyrrhenian Coast. Journal of Fish Biology 54 (6): 1300-1309. DOI: 10.1111/j.1095-8649.1999.tb02056.x
Deudero S., Morey G., Frau A., Moranta J., Moreno I. 2008. Temporal trends of littoral fishes at deep Posidonia oceanica seagrass meadows in a temperate coastal zone. Journal of Marine Systems 70 (1-2): 182-195.

DOI: $10.1016 /$ j.jmarsys.2007.05.001

Fox R.J., Bellwood D.R. 2008. Remote video bioassays reveal the potential feeding impact of the rabbitfish Siganus canaliculatus (f: Siganidae) on an inner-shelf reef of the Great Barrier Reef. Coral Reefs 27 (3): 605-615.

DOI: $10.1007 / \mathrm{s} 00338-008-0359-6$

Francour P. 1997. Fish assemblages of Posidonia oceanica beds at Port-Cros (France, NW Mediterranean): Assessment of composition and long-term fluctuations by visual census. Marine Ecology 18 (2): 157-173. DOI: 10.1111/j.1439-0485.1997.tb00434.x

Fréon P., Gerlotto F., Soria M. 1996. Diel variability of school structure with special reference to transition periods. ICES Journal of Marine Science 53 (2): 459 464.

DOI: $10.1006 /$ jmsc. 1996.0065

Fulton C.J., Bellwood D.R. 2002. Patterns of foraging in labrid fishes. Marine Ecology Progress Series 226: 135-142.

DOI: $10.3354 /$ meps 226135

Giakoumi S., Sini M., Gerovasileiou V., Mazor T., Beher J., Possingham H.P., Abdulla A., Çinar M.E., Dendrinos P., Gucu A.C., Karamanlidis A.A., Rodic P., Panayotidis P., Taskin E., Jaklin A., Voultsiadou E., Webster C., Zenetos A., Katsanevakis S. 2013. Ecoregion-based conservation planning in the Mediterranean: Dealing with large-scale heterogeneity. PLoS ONE 8 (10): e76449.

DOI: 10.1371/journal.pone.0076449

Gibson R.N., Pihl L., Burrows M.T., Modin J., Wennhage H., Nickell L.A. 1998. Diel movements of juvenile plaice Pleuronectes platessa in relation to predators, competitors, food availability and abiotic factors on a microtidal nursery ground. Marine Ecology Progress Series 165: 145-159. DOI: $10.3354 /$ meps 165145

Gordoa A., Molí B. 1997. Age and growth of the sparids Diplodus vulgaris, D. sargus and D. annularis in adult populations and the differences in their juvenile growth patterns in the north-western Mediterranean Sea. Fisheries Research 33 (1-3): 123-129. DOI: 10.1016/S0165-7836(97)00074-X

Gries G., Whalen K.G., Juanes F., Parrish D.L. 1997. Nocturnal activity of juvenile Atlantic salmon (Salmo salar) in late summer: evidence of diel activity partitioning. Canadian Journal of Fisheries and Aquatic Sciences 54 (6): 1408-1413. DOI: $10.1139 /$ cjfas-2012-0274

Guidetti P., Terlizzi A., Fraschetti S., Boero F. 2002. Spatio-temporal variability in fish assemblages associated with coralligenous formations in south eastern Apulia (SE Italy). Italian Journal of Zoology 69 (4): 325-331.

DOI: $10.1080 / 11250000209356477$ 
Hall K.C., Hanlon R.T. 2002. Principal features of the mating system of a large spawning aggregation of the giant Australian cuttlefish Sepia apama (Mollusca: Cephalopoda). Marine Biology 140 (3): 533-545.

DOI: $10.1007 / \mathrm{s} 00227-001-0718-0$

Hammerschlag N., Heithaus M.R., Serafy J.E. 2010. Influence of predation risk and food supply on nocturnal fish foraging distributions along a mangrove-seagrass ecotone. Marine Ecology Progress Series 414: 223-235. DOI: $10.3354 /$ meps08731

Hannah R.W., Blume M.T.O. 2012. Tests of an experimental unbaited video lander as a marine fish survey tool for high-relief deepwater rocky reefs. Journal of Experimental Marine Biology and Ecology 430-431: 1-9.

DOI: 10.1016/j.jembe.2012.06.021

Harmelin J.-G. 1987. Structure and variability of the ichthyo-fauna in a Mediterranean protected rocky area (National Park of Port-Cros, France). Marine Ecology 8 (3): 263-284.

DOI: $10.1111 /$ j.1439-0485.1987.tb00188.x

Harmelin J.-G. 1990. Ichtyofaune des fonds rocheux de Mediterranee: structure du peuplement du coralligene de l'ile de Port-Cros (Parc National, France). Mésogée 50: $23-30$.

Harvey E.S., Butler J.J., McLean D.L., Shand J. 2012. Contrasting habitat use of diurnal and nocturnal fish assemblages in temperate Western Australia. Journal of Experimental Marine Biology and Ecology 426427: 78-86.

DOI: $10.1016 /$ j.jembe.2012.05.019

Helfman G.S. 1981. Twilight activities and temporal structure in a freshwater fish community. Canadian Journal of Fisheries and Aquatic Sciences 38 (11): 1405-1420.

DOI: $10.1139 / \mathrm{f} 81-187$

Hobson E.S. 1972. Activity of Hawaiian reef fishes during the evening and morning transitions between daylight and darkness. Fishery Bulletin 70 (3): 715-740.

Hobson E.S. 1973. Diel feeding migrations in tropical reef fishes. Helgoländer wissenschaftliche Meeresuntersuchungen 24 (1-4): 361-370.

DOI: $10.1007 / \mathrm{BF} 01609526$

Horodysky A.Z., Brill R.W., Warrant E.J., Musick J.A., Latour R.J. 2008. Comparative visual function in five sciaenid fishes inhabiting Chesapeake Bay. Journal of Experimental Biology 211 (22): 3601-3612. DOI: $10.1242 /$ jeb.023358

Koeck B., Alós J., Caro A., Neveu R., Crechriou R., Saragoni G., Lenfant P. 2013. Contrasting fish behavior in artificial seascapes with implications for resources conservation. PLoS ONE 8 (7): e69303. DOI: 10.1371/journal.pone.0069303

Koeck B., Pastor J., Saragoni G., Dalias N., Payrot J., Lenfant P. 2014. Diel and seasonal movement pattern of the dusky grouper Epinephelus marginatus inside a marine reserve. Marine Environmental Research 94: 38-47.

DOI: 10.1016/j.marenvres.2013.12.002
Koeller P.A., Hurley P.C.F., Perley P., Neilson J.D. 1986. Juvenile fish surveys on the Scotian Shelf: Implications for year-class size assessments. ICES Journal of Marine Science 43 (1): 59-76.

DOI: $10.1093 /$ icesjms/43.1.59

La Mesa G., Molinari A., Gambaccini S., Tunesi L. 2011. Spatial pattern of coastal fish assemblages in different habitats in North-western Mediterranean. Marine Ecology 32 (1): 104-114. DOI: $10.1111 /$ j.1439-0485.2010.00404.x

Langlois T.J., Harvey E.S., Fitzpatrick B., Meeuwig J.J., Shedrawi G., Watson D.L. 2010. Cost-efficient sampling of fish assemblages: comparison of baited video stations and diver video transects. Aquatic Biology 9 (2): 155-168.

DOI: $10.3354 / \mathrm{ab} 00235$

Layton C., Fulton C.J. 2014. Status-dependent foraging behaviour in coral reef wrasses. Coral Reefs 33 (2): 345-349.

DOI: $10.1007 / \mathrm{s} 00338-014-1138-1$

Letourneur Y., Darnaude A., Salen-Picard C., Harmelin-Vivien M. 2001. Spatial and temporal variations of fish assemblages in a shallow Mediterranean soft-bottom area (Gulf of Fos, France). Oceanologica Acta 24 (3): 273-285.

DOI: 10.1016/S0399-1784(01)01146-X

López-Olmeda J.F., Madrid J.A., Sánchez-Vázquez F.J. 2006. Melatonin effects on food intake and activity rhythms in two fish species with different activity patterns: Diurnal (goldfish) and nocturnal (tench). Comparative Biochemistry and Physiology Part A: Molecular and Integrative Physiology 144 (2): 180-187.

DOI: 10.1016/j.cbpa.2006.02.031

Lowry M., Folpp H., Gregson M., Suthers I. 2012. Comparison of baited remote underwater video (BRUV) and underwater visual census (UVC) for assessment of artificial reefs in estuaries. Journal of Experimental Marine Biology and Ecology 416-417: 243-253.

DOI: 10.1016/j.jembe.2012.01.013

Mallet D., Wantiez L., Lemouellic S., Vigliola L., Pelletier D. 2014. Complementarity of rotating video and underwater visual census for assessing species richness, frequency and density of reef fish on coral reef slopes. PLoS ONE 9 (1): e84344.

DOI: 10.1371 /journal.pone.0084344

Martha K., Jones M. 2002. Behavioural overlap in six Caribbean labrid species: intra-and interspecific similarities. Environmental Biology of Fishes 65 (1): 71-81.

DOI: 10.1023/A:1019675323053

Milazzo M., Mirto S., Domenici P., Gristina M. 2013. Climate change exacerbates interspecific interactions in sympatric coastal fishes. Journal of Animal Ecology 82 (2): 468-477.

DOI: $10.1111 /$ j.1365-2656.2012.02034.x

Moranta J., Palmer M., Morey G., Ruiz A., MoralesNin B. 2006. Multi-scale spatial variability in fish 
assemblages associated with Posidonia oceanica meadows in the Western Mediterranean Sea. Estuarine, Coastal and Shelf Science 68 (3-4): 579-592.

DOI: $10.1016 /$ j.ecss.2006.03.008

Myers E.M.V., Harvey E.S., Saunders B.J., Travers

M.J. 2016. Fine-scale patterns in the day, night and crepuscular composition of a temperate reef fish assemblage. Marine Ecology 37 (3): 668-678.

DOI: $10.1111 /$ maec. 12336

Nagelkerken I., Van der Velde G., Gorissen M.W., Meijer G.J., Van't Hof T., Den Hartog C. 2000. Importance of mangroves, seagrass beds and the shallow coral reef as a nursery for important coral reef fishes, using a visual census technique. Estuarine, Coastal and Shelf Science 51 (1): 31-44.

DOI: $10.1006 /$ ecss.2000.0617

Noble M.M., Pratchett M.S., Coker D.J., Cvitanovic C., Fulton C.J. 2014. Foraging in corallivorous butterflyfish varies with wave exposure. Coral Reefs 33 (2): 351-361.

DOI: $10.1007 / \mathrm{s} 00338-014-1140-7$

Pelletier D., Leleu K., Mallet D., Mou-Tham G., Hervé G., Boureau M., Guilpart N. 2012. Remote highdefinition rotating video enables fast spatial survey of marine underwater macrofauna and habitats. PLoS ONE 7 (2): e30536.

DOI: 10.1371 /journal.pone.0030536

Piazzi L., Balata D., Cecchi E., Cinelli F., Sartoni G. 2009. Species composition and patterns of diversity of macroalgal coralligenous assemblages in the northwestern Mediterranean Sea. Journal of Natural History 44 (1-2): 1-22.

DOI: $10.1080 / 00222930903377547$

Piet G.J., Guruge W.A.H.P. 1997. Diel variation in feeding and vertical distribution of ten co-occurring fish species: consequences for resource partitioning. Environmental Biology of Fishes 50 (3): 293-307. DOI: 10.1023/A:1007390516552

Pink J.R., Fulton C.J. 2015. Fin spotting: efficacy of manual and video-based visual assessments of reef fish swimming behaviour. Journal of Experimental Marine Biology and Ecology 465: 92-98.

DOI: 10.1016/j.jembe.2015.01.008
Polunin N.V.C., Klumpp D.W. 1989. Ecological correlates of foraging periodicity in herbivorous reef fishes of the Coral Sea. Journal of Experimental Marine Biology and Ecology 126 (1): 1-20.

DOI: 10.1016/0022-0981(89)90121-4

Reebs S.G. 2002. Plasticity of diel and circadian activity rhythms in fishes. Reviews in Fish Biology and Fisheries 12 (4): 349-371. DOI: $10.1023 / \mathrm{A}: 1025371804611$

Reñones O., Moranta J., Coll M., Morales-Nin B. 1997. Rocky bottom fish communities of Cabrera Archipelago National Park (Mallorca, western Mediterranean). Scientia Marina 61 (4): 495-506.

Samoilys M.A. 1997. Periodicity of spawning aggregations of coral trout Plectropomus leopardus (Pisces: Serranidae) on the northern Great Barrier Reef. Marine Ecology Progress Series 160: 149-159. DOI: $10.3354 /$ meps 160149

Santos M.N., Monteiro C.C., Gaspar M.B. 2002. Diurnal variations in the fish assemblage at an artificial reef. ICES Journal of Marine Science 59 (Suppl): S32S35. DOI: $10.1006 /$ jmsc.2001.1166

Spyker K.A., Van Den Berghe E.P. 1995. Diurnal abundance patterns of Mediterranean fishes assessed on fixed transects by scuba divers. Transactions of the American Fisheries Society 124 (2): 216-224. DOI: 10.1577/1548-8659(1995)124<0216:DAPOMF >2.3.CO;2

Videler J.J. 1986. Sleep under sand cover of the labrid fish Coris julis. Pp. 145-147. In: Koella W.P., Obal F., Schulz H. (eds.) Phylogeny of sleep. Gustav Fischer Verlag, Stuttgart, New York.

Watson D.L., Harvey E.S., Anderson M.J., Kendrick G.A. 2005. A comparison of temperate reef fish assemblages recorded by three underwater stereovideo techniques. Marine Biology 148 (2): 415-425. DOI: $10.1007 / \mathrm{s} 00227-005-0090-6$

Willis T.J., Badalamenti F., Milazzo M. 2006. Diel variability in counts of reef fishes and its implications for monitoring. Journal of Experimental Marine Biology and Ecology 331 (1): 108-120. DOI: $10.1016 /$ j.jembe.2005.10.003

Received: 9 May 2016 Accepted: 25 August 2016 Published electronically: 30 September 2016 